\title{
AS DIMENSÕES SOCIAIS DOS COSTUMES FUNERÁRIOS ENTRE OS MICENIOS: OS CIRCULOS TUMULARES A E B DE MICENAS
}

\author{
Ana Claudia Torralvo \\ Faculdade de Filosofia, Letras e Ciências Humanas \\ Universidade de São Paulo
}

Resumo: $O$ Linear $B$ é a escrita micênica e comprovadamente a forma mais antiga conhecida de registro da língua grega. Contudo, é representada apenas por arquivos palacias, registros burocráticos de transaçốes comerciais. Muito pouco é conhecido da sociedade que construiu as poderosas muralhas de Micenas e Tirinto (Argólida) e 0 grande palácio de Pilos (Messênia). Este artigo trata do período de formação dessa sociedade já que os Circulos Tumulares de Micenas são praticamente os únicos vestígios desse período. Analisando as estruturas funerárias e seu mobiliário nos é possível detectar pistas que nos ajudam a formular novas hipóteses. Estas novas hipóteses, por sua vez são vistas através de um prisma arqueológico e antropológico que nos revelam aspectos muito mais concretos de uma civilização conhecida somente através de seus restos materiais.

Palavans-Chave: Arqueologia Micênica, Abordagem Antropológica, Ideologia da Morte

\section{INTRODUĢAO}

Até o final do século passado os poemas homéricos eram a única fonte sobre a era aquéia. Um universo mítico de reis e cavaleiros portava em seu âmago os princípios éticos e morais da civilização grega. Apesar de ser apenas uma lenda, Henrich Schliemann acreditava na realidade do mito e sua fé inabalável em Homero fê-lo encontrar Tróia, após o que foi em busca de Micenas: a cidade de Agamenon, senhor dos aqueus e possivel capital da confederação. Em 1876, escavou a cidadela de Micenas e al julgou ter encontrado os túmulos dos her6is mortos quando de seu retorno de Tróia (Figura 1). Assim, às três estruturas monumentais ou Tholoi que encontrou próximas à cidadela chamou: Tesouro de Atreu, Túmulo de Clitemnsetra e Túmulo de Egisto (estes dois áltimos, assim denominados por estarem fora do perímetro das muralhas da cidadela). No interior dos muros encontrou um grande círculo limitado por um muro e com uma entrada, al foram escavados por ele cinco grandes sepulturas, os túmulos em poço. A riqueza neles encontrada fez com que Schliemann julgasse ter encontrado os sepulcros de Agamenon e seus companheiros. Infelizmente para Schliemann, o desenvolvimento da arqueologia e 0 estudo estratigráfico deste círculo comprovaram que ele estava errado. Contudo, sua crença na veracidade do mito deu início aos estudos da proto-história grega e 0 que era apenas uma lenda passou a materializar-se, campanha após campanha de escavaçōes, revelando-nos a civilização micênica. 
A esse primeiro círculo escavado foi dada a designaçăo de Círculo Tumular A. Setenta anos após, de 1952 a 1954, durante os trabalhos de reconstrução da Tholos conhecida como Túmulo de Clitemnsetra, foram encontrados diversos túmulos, perfazendo um total de 24, escavados por I. Papademetriou e por $\mathbf{G}$. Mylonas que comprovaram fazerem parte de outro círculo, mais ou menos contemporåneo ao outro, o qual designaram Círculo Tumular B.

A diferença fundamental entre ambos os Circulos Tumulares no que concerne à pesquisa está nos métodos de escavaçăo e documentaçăo utilizados. Apesar do bom trabalho de Schliemann, que utilizou todos os recursos disponiveis em sua época, podemos observar pela qualidade e quantidade dos dados obtidos nas campanhas de 1952-4 o desenvolvimento da técnica arqueológica.

\section{Localizaça e Cronologia dos Ciaculos tumulares}

Os Círculos Tumulares situam-se cronológicamente, nos primórdios do Periodo Micênico, abrangendo a transição do Heládico Médio III para o Heládico Recente $\mathrm{I}^{1}$. 0 Círculo Tumular $\mathrm{B}$ é mais antigo que o $\mathrm{A}$ sendo as dataçōes mais comumente aceitas 1650-1550 a. C. para o periodo de utilização do Círculo Tumular B e 1600-1500 a. C. para o período de utilização do Círculo $A^{2}$ (Treuil, et alii, 1989, p. 326) (Figura 2).

Estes círculos distam aproximadamente $150 \mathrm{~m}$ um do outro, estando do lado oeste da Acrópole de Micenas que domina o NE da planície de Argos.

\section{Os CÍRCULOS TUMULARES}

A importância destes túmulos reside principalmente no fato de serem os únicos testemunhos do período de transição HM-HR. As mudanças ocorridas nesse período podem ser percebidas como resultado de desenvolvimentos locais e não como penetrações estrangeiras agressivas (invasões, guerras, dominação). Essa fase de transição é designada como proto-micênica, momento no qual a civilização passou de um estágio de formação para o estágio de expansão.

Para podermos compreender os Círculos Tumulares de Micenas é necessário que observemos rapidamente as práticas funerárias que prevaleceram durante o. Heládico Médio. Num primeiro momento, as sepulturas são individuais, na forma de cistas, poços cavados na terra ou pithoi, dentro dos limites das habitações (no seu interior ou nas imediações); o mobiliário funerário, ou seja, os objetos que são depostos junto ao morto, na grande maioria dos casos, é inexistente ou restringem-se a apenas um recipiente ceråmico. Já num segundo momento, no final do HM, além das sepulturas individuais aparecem túmulos com sepultamentos múltiplos, ou seja, túmulos reutilizáveis que eram reabertos a cada novo enterramento. Tal estrutura acarreta dois fatores que afetam diretamente a construção: primeiramente o tamanho, pois tais túmulos deveriam ser bem maiores

10 Heládico é a denominaçăo dada ao período da ldade do Bronze no continente grego, assim como Minóico corresponde ao mesmo periodo em Creta e Cicládico as ithas Ciclades Como a Idade do Bronze, esses períodos são subdivididos em Antigo, Médio e Recente

2 Para informações técnicas mais especificas sobre os Clrculos Tumulares conferir 0 Pelon 
e em segundo lugar, a necessidade de um acesso intermitente. Começam a aparecer os primeiros cemitérios intra e extra muros e o mobiliário agora apresenta-se mais abundante em alguns lugares.

O Circulo Tumular B (Mee \& Cavanagh, 1984, p. 46), como já foi dito, é o mais antigo com aproximadamente $27 \mathrm{~m}$ de diâmetro, medida essa presumida a partir dos vestígios do muro de cercamento. Apresenta 24 túmulos dos quais um pertence ao Heládico Médio II, 21 ao Heládico Médio III e dois à transição do Heládico Médio III para o Heládico Recente I. Dentre eles 12 possuem um comprimento superior a $2 \mathrm{~m}$, e destes 7 têm um comprimento acima de $3 \mathrm{~m}$. Com exceção do Túmulo $\mathrm{Pi}$, o mais antigo, que é uma cista, todos os outros apresentam uma estrutura mais elaborada: o poço aumenta de tamanho e tanto o piso como as paredes passam a receber um revestimento em alvenaria de tijolos crus e/ou pedras, aparece também uma estrutura de madeira que serviria para sustentar as lajes da cobertura a qual receberia uma camada de argila hidrofila para proteger 0 túmulo de infiltrações. Somente três dos 24 túmulos não apresentam essa estrutura (Figura 3).

0 Círculo Tumular $A$ apresenta um diâmetro interno de $26 \mathrm{~m}$ e ocupa um terreno de forte inclinação Leste-Oeste. A porção Leste não apresenta túmulos pois é constitulda de rocha dura. Está cercado por um duplo anel de lajes, semelhante aos vestígios encontrados no Círculo B, com uma entrada do lado Norte. Al foram escavados seis túmulos: três apresentam um comprimento superior a $5 \mathrm{~m}$ e nenhum deles tem comprimento inferior a $3 \mathrm{~m}$. Algumas análises comprovam que o Círculo Tumular $A$ não cobre mais de duas gerações, talvez 50 anos, e que toda a seqüência dos túmulos em poço cobriria quatro ou, no máximo, cinco gerações, abrangendo assim um período não superior a um século (Figura 4).

0 que percebemos na seqüência de evolução do Círculo Tumular B para 0 A é uma tendência cada vez maior para deposições múltiplas, o que acarretou, do ponto de vista estrutural, um aumento considerável no tamanho dos tumulos se comparados à cistas individuais utilizadas no Heládico Médio II (Dickinson, 1972, p. 146). Tal aumento de tamanho foi acompanhado das conseqüentes alterações estruturais necessárias como, por exemplo, construção mais aprimorada das paredes de sustentação e da sofisticação cada vez maior do sistema de cobertura, 0 qual deveria proteger o túmulo e facilitar a sua reutilização. 0 mobiliário apresentase, no decorrer do período de utilização de ambos os Círculos, cada vez mais rico e abundante (Mee \& Cavanagh, 1984, p. 47), tendo como ponto extremo o túmulo IV do Círculo Tumular A. Nele foram sepultadas cinco pessoas (três homens e duas mulheres) tendo sido encontrado: oito diademas, três máscaras fúnebres em ouro, 27 espadas e mais de 600 rosetas para decoração de vestimentas em ouro dentre outros artefatos (Treuil et alii, 1989, p. 327) (Figura 5).

Durante 0 periodo de utilização do Círculo Tumular B de Micenas podemos encontrar túmulos comparáveis em outras partes da Planície de Argos como os túmulos em poço de Lerna, o tumulus de Asine e as sepulturas de Kheliotomylos. Contudo, no período de utilização do Círculo Tumular A de Micenas nada é encontrado de similar no ambito da Planicie. Nos outros sítios continuam a ser utilizadas as cistas, como em Lerna, e algumas formas primitivas de cåmaras tumulares, como em Prosymna. A vasta acumulação de material que nos revelam os túmulos de Micenas não pode ser encontrada em nenhum outro sítio da Planície de Argos durante esse período inicial do Heládico Recente I. Todo esse material é 
caracterizado por uma heterogeneidade, a qual deve ser ressaltada. Excetuando-se os conjuntos de ornamentos que compunham a vestimenta, é muito dificil encontrar objetos idênticos ou mesmo muito parecidos. Tal situação suscita duas hipoteses: a primeira, e mais comumente aceita, é a de penetração de indústrias estrangeiras no continente grego durante o final do Heládico Médio, indústrias essas que se estabelecem pela ausência de uma forte tradição anterior. Em segundo lugar, levanta-se mais recentemente a hipóstese da existência de artesãos que produzissem "objetos de arte", obras únicas e de alto valor no sentido da dificuldade de execução.

\section{Conclusóes}

Esta situação apresentada pelos vestígios funerários micênicos do início do Heládico Recente nos deixa clara, através da evolução estrutural notada do Círculo Tumular B para o A, já citada anteriormente, a emergência gradual de uma elite. Em oposição à sociedade homogênea do Heládico Médio, refletida pela simplicidade dos túmulos, temos agora estruturas que exigem uma considerável mão-de-obra se comparada com as estruturas anterioremente usadas, as quais muito raramente ultrapassam $1 \mathrm{~m}$ de comprimento. A monopolização de mão-deobra com a finalidade de construção de um túmulo exige que haja uma certa concentração de poder nas mãos dessa elite emergente. Os túmulos muito maiores agora são construídos para a constante reutilização o que afirma um caráter familiar de tais túmulos e salienta, por sua vez, o mesmo caráter familiar e possívelmente dinástico dessa elite concentradora de poder. Outro fator importante para a caracterização dessa elite é o mobiliário que, como a estrutura, aparece cada vez em maior quantidade e riqueza na evolução do Círculo Tumular $\mathrm{B}$ para $\circ \mathrm{A}$, como exemplo voltemos a citar as máscaras mortuárias: no Círculo Tumular B foi encontrada apenas uma máscara em nielo (liga de ouro e prata, muito utilizada pelos micênios), enquanto que no Círculo Tumular $A$ foram encontradas cinco máscaras em ouro, sendo três provenientes do túmulo IV.

Mas qual seria a forma de desenvolvimento político dessa elite emergente? Qual a causa de seu enriquecimento repentino no final do Heládico Médio, especialmente e em particular em Micenas? É comumente aceito que os habitantes do continente grego tomaram ou herdaram a dominação do Egeu, estabelecida pela sociedade palacial de Creta da Idade do Bronze Médio; e que essa dominação foi construída grandemente em bases comerciais, talvez governada por um sistema administrativo e militar, que inicialmente ligou Creta ao Oriente Próximo. Assim, notamos que nossa noção das origens da sociedade micênica está ligada à teoria antropológica onde sociedades altamente organizadas estimulam seus vizinhos menos organizados a desenvolverem uma organização mais estruturada. Isso também pode ser visto da seguinte forma: as tensões e conflitos que possam surgir entre grupos sociais diferentemente estruturados podem resultar tanto em guerras como em competição econômica e tecnológica. Esse processo durou um certo tempo, não só para aprender com os minбicos, mas também para criar uma estrutura política interna estável através da institucionalização de seus próprios costumes. 0 princípio ativo desse processo começou claramente no período dos 
Círculos Tumulares A e B e está estreitamente ligado ao enriquecimento daqueles principes (Wright, 1984, p. 65-70).

0 comércio foi o caminho pelo qual ocorreu a transmissão da informação que estimulou a formação de unidades politicas locais incipientes no continente grego. Esse contato parece ter impulsionado o processo de diferenciação social, bem como ofereceu as condições materiais para desencadear tal processo.

Nos túmulos do período do Heládico Médio há uma pequena, quase imperceptivel, diferenciação dos estratos mais antigos para os mais recentes, que refletem poucas mudanças na constituiçăo da sociedade do Heládico Médio, caracterizado pela homogeneidade da forma dos assentamentos de Etreusis e Lerna e os tipos funerários estão agrupados em tumului comunais e cemitérios de cistas, nem sempre bem acabadas, muitas vezes feitas com material que estivesse à disposição. Somente quando começaram a aparecer itens de importação percebe-se uma mudança de natureza. Notamos então os seguintes requisitos na informação arqueológica do processo de estratificação social:

a. aparecem evidências de melhoria nutricional para poucos em Micenas;

b. diferenciação dos tipos funerários no que se refere às estruturas como o aparecimento de túmulos em poço, na distribuição com os Círculos Tumulares, e no conteúdo com a riqueza dos túmulos em poço;

c. evidência de um poder coercivo a qual pode ser atestada pela grande quantidade de espadas e adagas nos túmulos em poço; $e$

d. acesso especial a itens de prestigio demonstrado pela joalheria em ouro e prata. Encontramos pois os requisitos básicos que sugerem 0 estabelecimento de um sistema hereditário de transferência de poder, que resulta de sua institucionalizaçāo. Demonstra a natureza multifacetada desse processo de desenvolvimento social envolvendo atividades simbolicas, informativas, econômicas e politicas.

A importância de todo esse processo perpetuou-se na memória dos habitantes locais e reflete-se durante 0 Heládico Recente IIIB, aproximadamente 1400 a. C., quando foram executadas obras de reforço das muralhas da cidadela e a inclusão do que havia restado do Circulo Tumular A dentro dessas muralhas. Foi levada a cabo uma completa reforma do circulo com obras de aplainamento interno, reconstrução do círculo, recolocação de marcos ou estelas e contrução de um altar. Isso que vemos hoje em Micenas são os restos datados dessa época, quando, por algum motivo que ainda nos ó obscuro, reafirmou-se arquitetónicamente um passado glorioso, ressaltando o caráter ancestral dos individuos al enterrados através da construção de um altar de culto. É a afirmação de seu poder através de sua propria historia. 
Aostract: The Linear $B$ is the mycenaean writing and surely the oldest form of the greek language registration. However, it's represented only by palatial archives, burocratic records of comercial exchanges. Only a little is known about the society that had built the powerful walls of Mycenae and Tyrinte (Argolid) and the palace of Pylos (Messenie). This paper discuss the formation's period of that society, seeing that the Grave Circles of Mycenae are praticaly the only trace from that period. In analysing the mortuary estructures and grave goods it became possible to detect some traces that help us to formulate new questions. The new hypothesis are seen from a archaeologic and anthropologic point of view that refer us to some aspects of a civilisation known principally by your material remains.

Bibliografia

DICKINSON, O. T. P. K. The shaft graves and mycenaean origins. Institute of Classical Studies Bulletin, n. 19, 1972, p. 146-147.

GATES, Ch. Rethinking the building history of grave circle $A$ at Mycenae. American Journal of Archaeology, n. 89, 1985, p. 263-274.

HOOKER, J. C. Mycenaean Greece. Londres: Routledge \& Kegan Paul, 1976.

HOPE SIMPSON, R. Mycenaean Greece. Nova Jersey: Noyes Press, 1981.

MEE, C. B., CAVANAGH, W. G. Mycenaean tombs and social organization. Oxford Journal of Archaeology, n. 45, 1984, p. 45-64.

MYLONAS, G. E. The cemeteries of Eleusis and Mycenae. In: Proceedings of the American Philosophical Society, 99(1955) 57-67.

PELON, 0. Tholoi, tumuli et cercles funeraires. Paris: De Boccard, 1976.

TORRALVO, A. C. Os costumes funerários e a sociedade micênica: o exemplo da Planicie de Argos. Inédito.

TREUIL, R., DARCQUE, P., POURSAT, J.-C., TOUCHAIS, G. (dir.) Les civilisations égéennes du Néolithique et de l'Age du Bronze (Nouvelle Clio 1 ter). Paris: Presses Univers. de France, 1989.

WRIGHT, J. C. Umpiring the mycenaean empire. Temple University Aegean Symposium, n. 9, 1984, p. 58-70. 
285

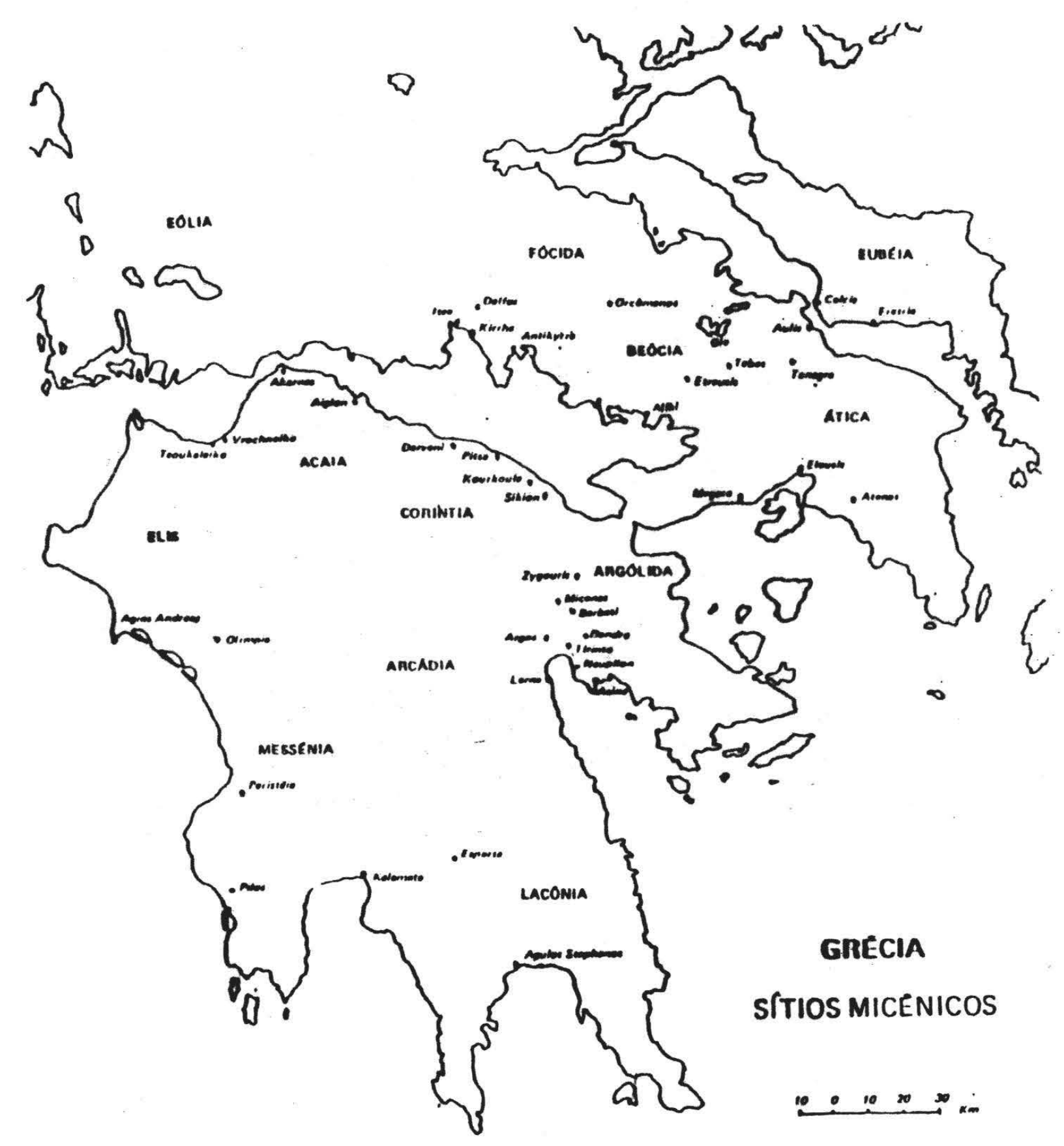

Fig. 1. Sítios Micênicos. 


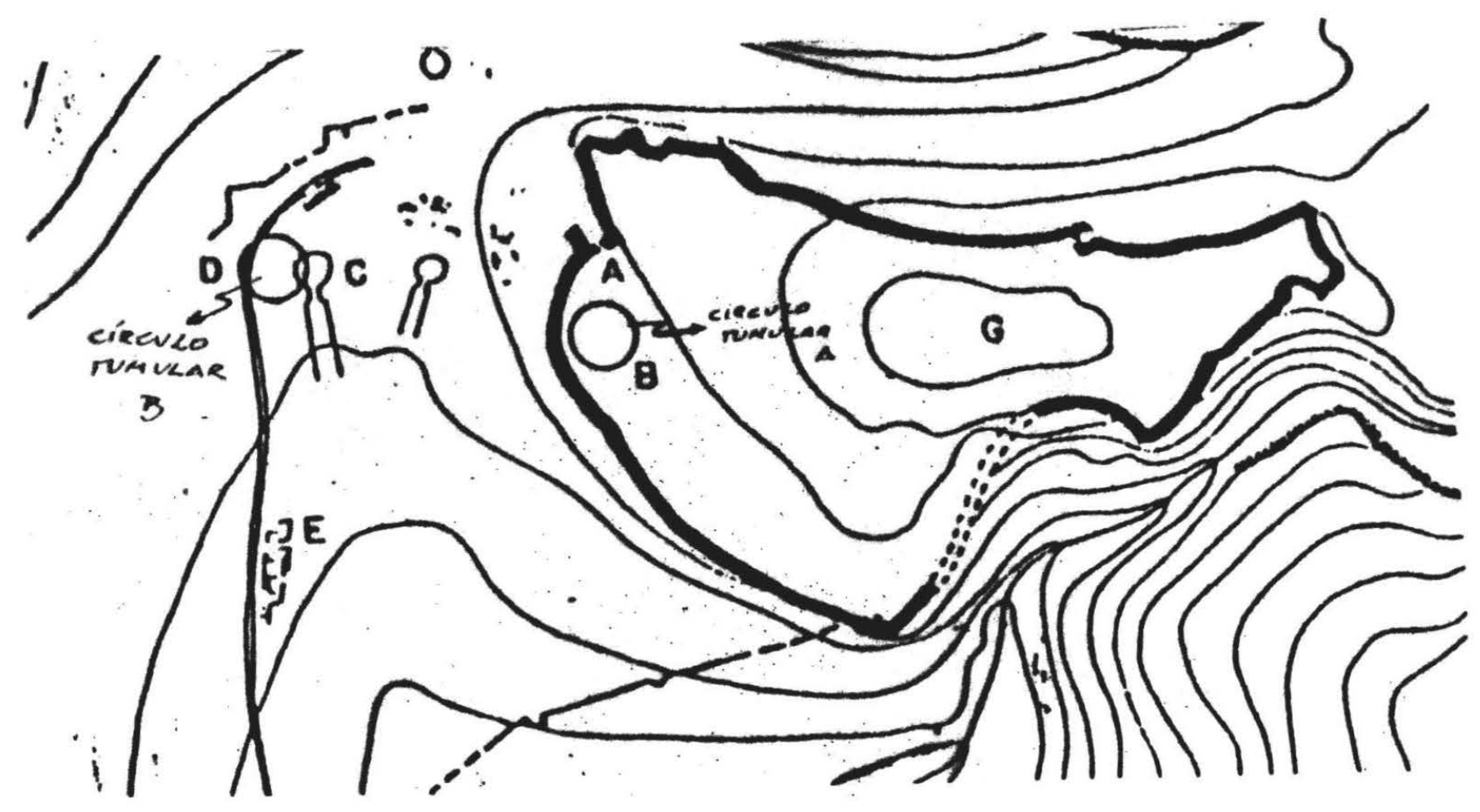

Fig. 2. Micenas: a cidadela e seus arredores 


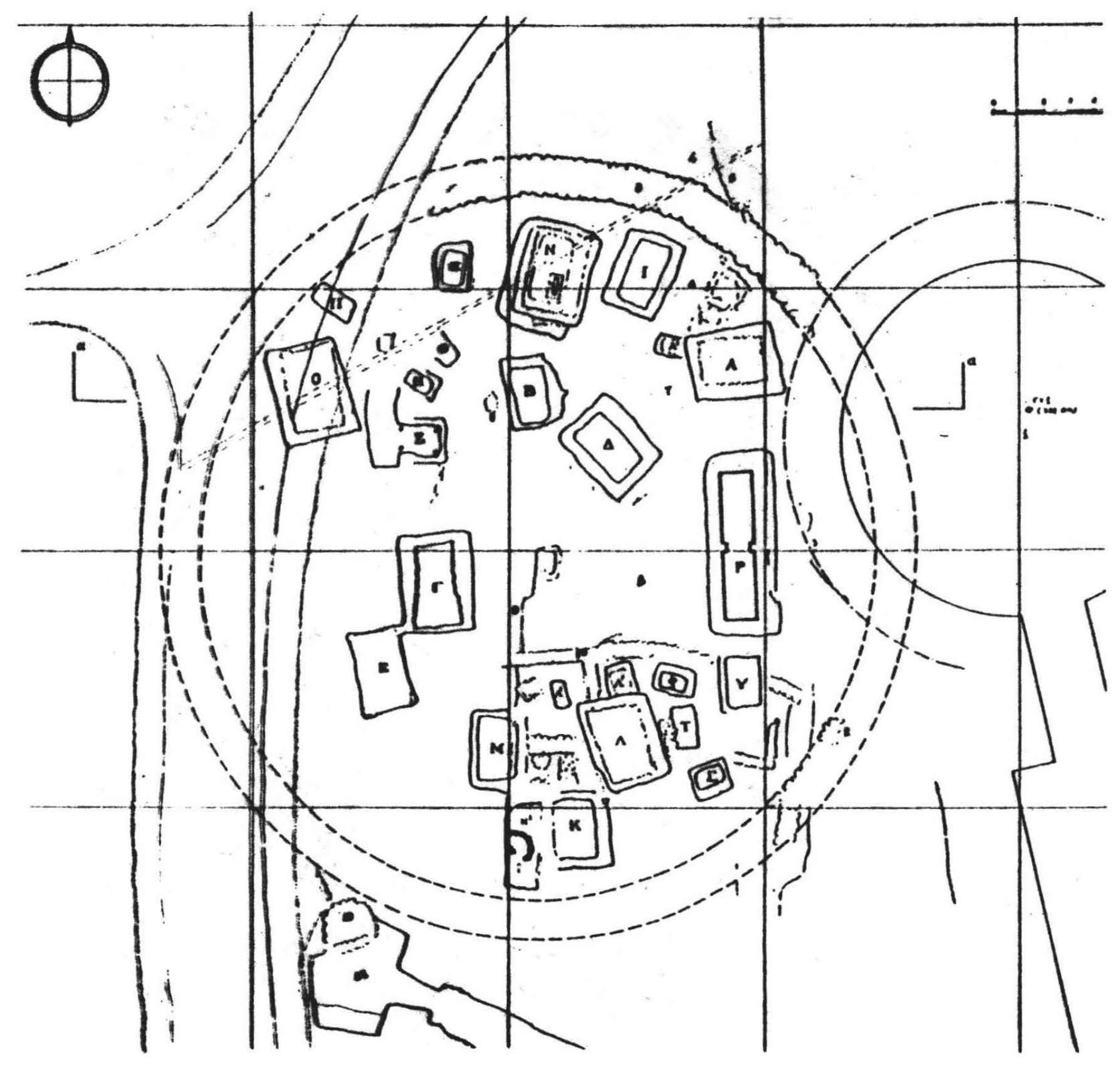

Fig. 3. 0 Círculo Tumular B. 


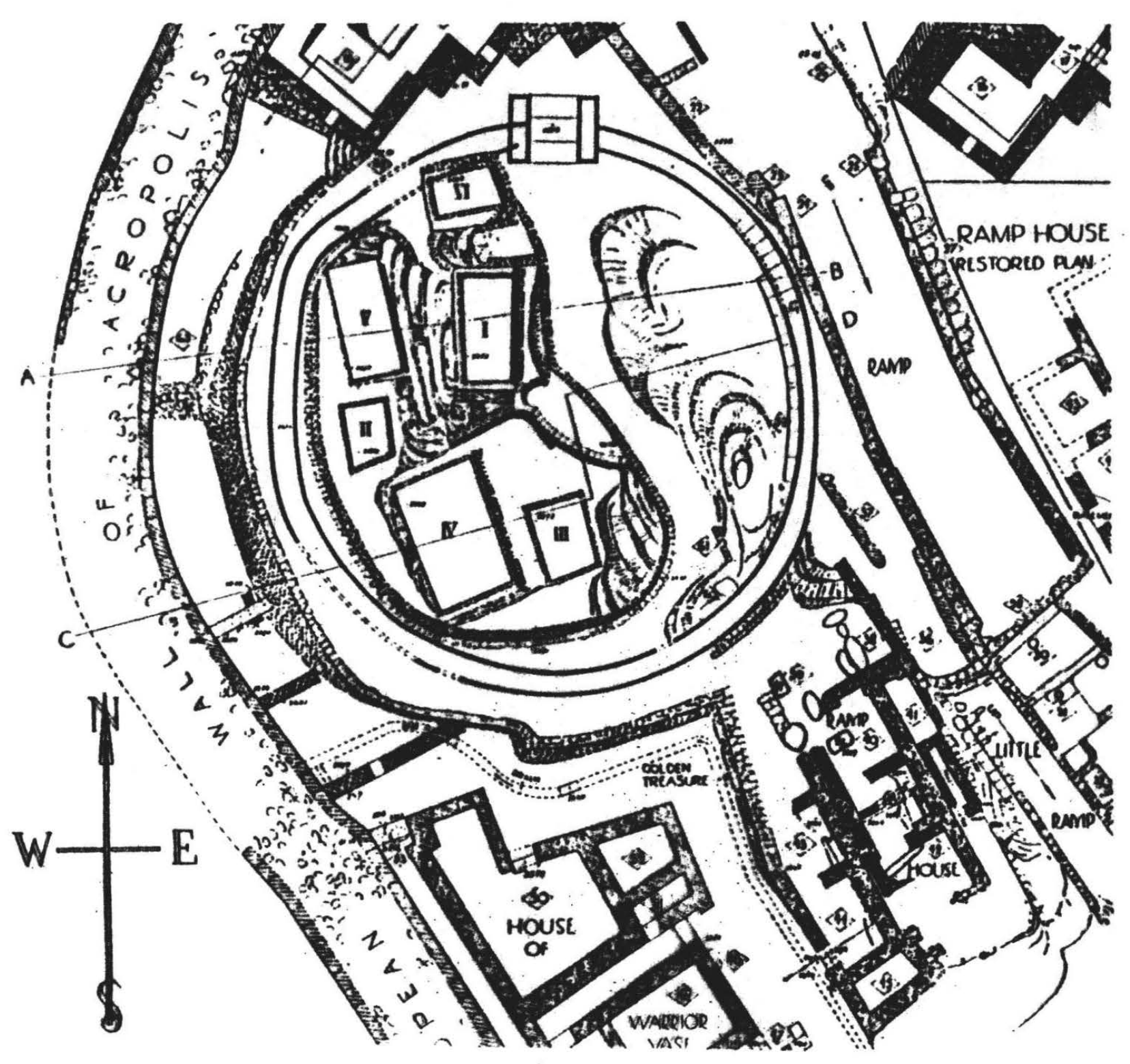

Fig. 4. O Círculo Tumular A. 


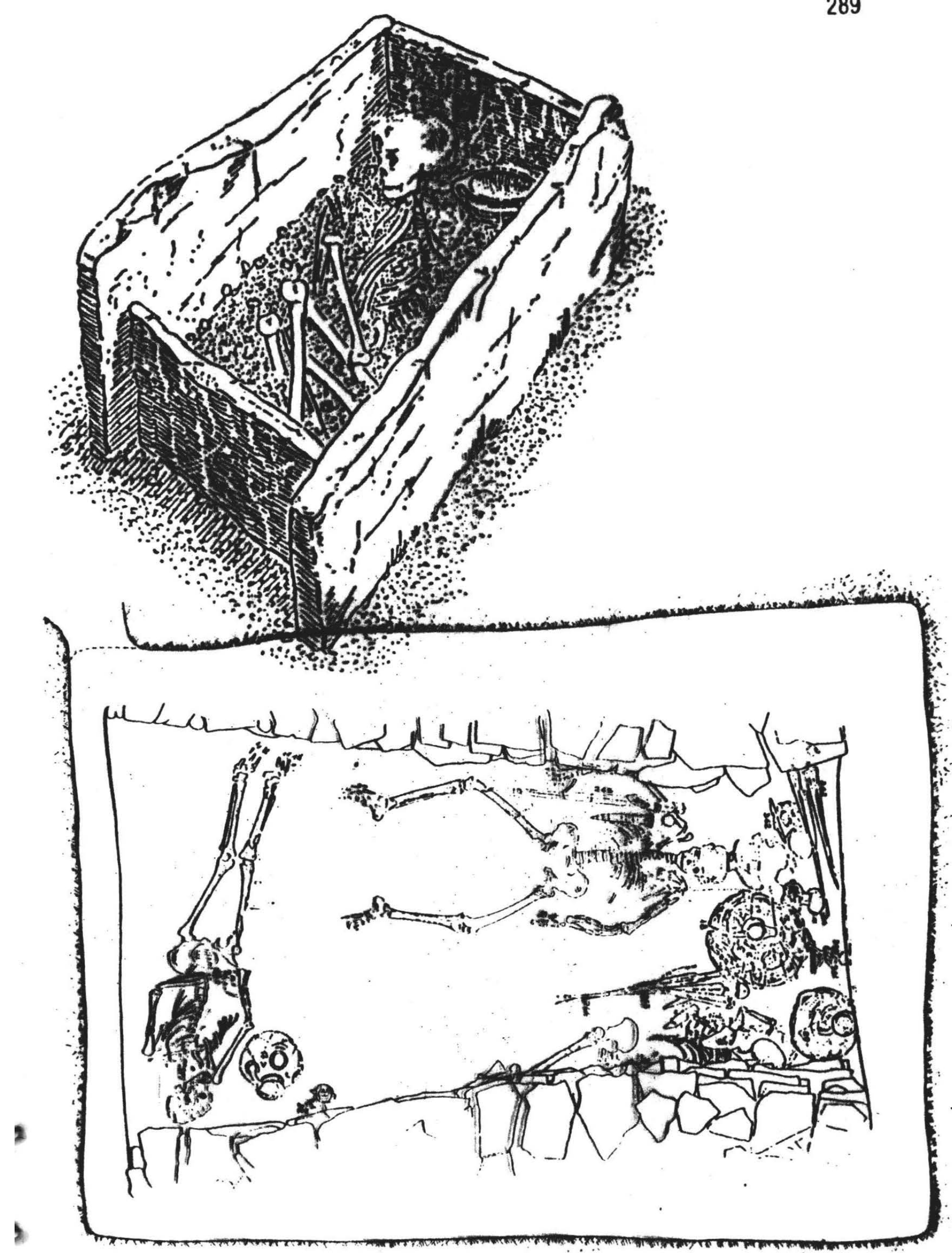

TUMULO $r$

Fig. 5. Cista meso-hedálica e túmulo em poço do Círculo Tumular B (Túmulo Gama). 